\title{
DESINTERESSE ESCOLAR: Um Estudo Sobre o Tema a Partir de Teses e Dissertações
}

\author{
Ana Luiza Casasanta Garcia ${ }^{1}$ \\ Karine Raquiel Halmenschlager ${ }^{2}$ \\ Elizandro Maurício Brick ${ }^{3}$
}

\begin{abstract}
RESUMO
Este trabalho tem como objetivo apresentar um panorama da produção acadêmica a respeito da temática "desinteresse escolar" a partir do mapeamento de teses e dissertações que abordam o assunto. Metodologicamente, realizou-se uma revisão de literatura sistemática no banco de teses e dissertações da Capes, quando foram localizados 46 estudos. A análise foi realizada por meio da leitura do título e do resumo dos trabalhos, com base nas seguintes categorias emergentes: (1) desinteresse pela educação escolar; (2) implicações do desinteresse do aluno na atividade docente; (3) desinteresse como uma construção histórico-social; ligado a aspectos sociais e (4) desinteresse associado à indisciplina, abandono, evasão e desempenho escolar. Entre os resultados, destaca-se que apesar de a escola ser entendida como um espaço significativo para adquirir conhecimentos e ser uma "promessa para um futuro melhor", a falta de interesse dos estudantes é um fenômeno presente e que marca tanto a trajetória escolar destes quanto afeta a saúde mental do corpo docente. Foi possível inferir, ainda, que o desinteresse envolve diferentes dimensões, podendo estar relacionado tanto a disciplinas específicas quanto ao processo de aprendizagem escolar de modo geral.
\end{abstract}

Palavras-chave: Desinteresse escolar. Educação escolar. Teses e dissertações.

\section{LACK OF INTEREST IN SCHOOL: A STUDY BASED ON THESES AND DISSERTATIONS}

\section{ABSTRACT}

This paper aims to present an overview of academic production on the theme "school disinterest" from the mapping of theses and dissertations that address the subject. Methodologically, a systematic literature review was performed in the thesis and dissertation by Capes database. So 46 studies were located. The analysis was performed by reading the title and the abstract, based on the following emerging categories: (1) lack of interest in school education; (2) implications of student disinterest in teaching activity; (3) disinterest as a socio-historical construction; linked to social aspects and (4) disinterest associated with indiscipline, dropout, dropout and school performance. Among the results, it is noteworthy that although the school is understood as a significant space to acquire knowledge and to be a "promise for a better future", the students' lack of interest is a present phenomenon and that marks both their school trajectory, how much it affects the mental health of the faculty. It was also possible to infer that disinterest involves different dimensions and may be related to both specific subjects and the school learning process in general.

Keywords: School disinterest. School education. Thesis and dissertations.

Recebido em: 10/11/2019

Aceito em: $2 / 1 / 2020$

\footnotetext{
1 Autora correspondente. Universidade Federal de Santa Catarina - UFSC. Campus Universitário Reitor João David Ferreira Lima, s/n, Trindade. Florianópolis/SC, Brasil. CEP 88040-900. http://lattes.cnpq.br/0164153254097429. https://orcid.org/0000-0002-3947-273X. analuizagarcia@hotmail.com

2 Universidade Federal de Santa Catarina - UFSC. Florianópolis/SC, Brasil. http://lattes.cnpq.br/4737190204025680. https://orcid.org/00000003-2747-3601.

3 Universidade Federal de Santa Catarina - UFSC. Florianópolis/SC, Brasil. http://lattes.cnpq.br/2410455109298846. https://orcid.org/00000002-6890-9566.
} 
Considerada um pré-requisito necessário da liberdade civil, a educação configura-se como um direito humano necessário ao exercício da cidadania (MARSHALL, 1967). A efetivação desse direito, no entanto, requer uma série de condutas, ações e políticas que levem em consideração tanto a conjuntura estatal como as desigualdades sociais presentes em nossa sociedade (CURY, 2002).

No âmbito dessa tarefa de promover e incentivar a educação, especificamente para a efetivação do direito à educação escolar num país diverso e de dimensões continentais com o Brasil, grandes desafios já foram enfrentados e há outros que se apresentarão. Entre eles podemos citar os direitos conquistados na esfera formal, como a obrigatoriedade dos oito anos de ensino para todas as crianças nas décadas de 70 e 80 (BRASIL, 1971), o que propiciou uma popularização do acesso à educação escolar às camadas da sociedade antes não assistidas. Isso trouxe também, contudo, demandas de distintas ordens, como a expansão das redes de ensino, o aumento do número de professores, a ampliação da oferta de formação de professores e - conforme elucidam os estudos sobre evasão escolar, realizados principalmente na década de 90 , quando esses desafios eram enfrentados - a transformação da forma-escolar propedêutica, voltada exclusivamente para as classes dominantes, que gerava dificuldades de acolher alunos oriundos de outras realidades sociais.

Mesmo, entretanto, que tenhamos, desde a Lei de Diretrizes e Bases (LDB) número 9.394/96 (BRASIL, 1996), uma finalidade explicitamente não propedêutica da Educação Básica e, inclusive, a meta de universalização do Ensino Médio a partir de 2009 (BRASIL, 2009), ainda não se efetivou o acesso universal à educação escolar no Brasil. De acordo com o Inep 2,8 milhões de crianças e jovens na faixa de 4 a 17 anos não frequentavam a escola em 2015 (INEP, 2017). Deste total, 771.982 correspondem às crianças em idade escolar que deveriam ingressar no Ensino Fundamental e que não estão matriculadas. Igualmente o Brasil, de acordo com dados do IBGE (PNAD Contínua 2018 - Educação) tem pelo menos 11,3 milhões de pessoas com mais de 15 anos analfabetas (6,8\% de analfabetismo).

A partir dessas informações, entendemos que o acesso à educação escolar se configura como um dos desafios que ainda precisam ser enfrentados. Não obstante, outros tensionamentos, que dificultam a efetividade do direito à educação, são constantemente vivenciados, mesmo que o estudante tenha acesso à escola. Entre eles o desinteresse dos estudantes e também as implicações que esse desinteresse pode causar em sua vida, na vida escolar e na prática dos profissionais da educação.

$O$ desinteresse também encontra-se na lista dos principais motivos de baixa frequência escolar elencados pelo Ministério da Educação (MEC) do Brasil. Estes motivos de baixa frequência são resultado de um trabalho contínuo de mais de uma década de acompanhamento bimestral da frequência escolar de alunos beneficiários do programa Bolsa Família, realizado por uma rede de acompanhamento coordenada pelo MEC. ${ }^{4}$

${ }^{4}$ Em 2017 foi realizado o acompanhamento da frequência escolar de 16,7 milhões de crianças e adolescentes em situação de pobreza, beneficiárias do PBF (MEC, Sistema Presença, 2017). 
O levantamento de dados realizado pela Secretaria de Educação Continuada, Alfabetização, Diversidade e Inclusão, do Ministério da Educação (Secadi/MEC), em 2016, constatou como segundo maior motivo de baixa frequência escolar o desinteresse/desmotivação, registrando 158.777 das ocorrências, abaixo do motivo de tratamento de doença e de atenção à saúde do aluno (205.695) e, acima, respectivamente, dos registros de abandono escolar/desistência (137.703) e negligência dos pais ou responsáveis (117.090). O número público do período foi 16,2 milhões de crianças e adolescentes de 6 a 17 anos.

No âmbito da literatura, a temática "desinteresse escolar" é pauta de diversas discussões, sob diferentes abordagens. Há estudos que investigam os fatores que contribuem e/ou desencadeiam o desinteresse pela aprendizagem de modo geral (MORALES; ALVES; 2016; BAZILIO, 2009) ou por determinadas disciplinas escolares (MARIANO; MIRANDA; METZNER, 2017; BITENCOURT; BATISTA, 2011; CIMA et al., 2017). São significativos também os trabalhos que discutem o fracasso e a evasão escolar e os relacionam com o desinteresse dos estudantes pelo processo de ensino e aprendizagem e/ou escola (SILVA, 2016; POZZOBON; MAHENDRA; MARIN, 2017; ANGELUCCl et al., 2004).

Diante deste contexto, e da evidente emergência de se ampliar as discussões sobre o desinteresse escolar, este artigo tem como objetivo apresentar um panorama da produção acadêmica a respeito da temática "desinteresse escolar", a partir do mapeamento de teses e dissertações disponíveis no banco de dados da Capes. Espera-se que as discussões apresentadas neste estudo contribuam para identificar os principais fatores associados ao desinteresse escolar, no campo da pesquisa.

\section{DESINTERESSE ESCOLAR}

Para entendermos o desinteresse devemos, inicialmente, compreender o sentido etimológico da palavra "interessante", que significa "estar em". Quando "estamos em" algo, portanto, estamos interessados, participativos, estamos e queremos estar envolvidos naquilo. A noção de desinteresse é o contrário disso: quando estamos desinteressados, não "estamos em", não queremos participar e há a busca pelo afastamento daquilo que nos desinteressa.

Ao pensarmos no espaço escolar, não é incomum que já tenhamos escutado que o estudante é preguiçoso, "faz corpo mole" e tantas outras formas que dizem que ele "não está" interessado em fazer qualquer coisa na escola. Chamamos isso de desinteresse escolar, algo reconhecido popularmente como um grande desafio. Por quais razões, porém, os estudantes estariam desinteressados? Pelo que eles teriam desinteresse? Quais os impactos do desinteresse no âmbito escolar e para a vida dos estudantes? Como se pode explicar o desinteresse dos alunos? O que faz a escola ser ou não interessante para o estudante?

Problematizações como estas são objetos de estudo que intrigam diversos campos de conhecimento, tais como a educação, ensino, Psicologia, Antropologia, Sociologia, entre outros. De acordo com Krapp e Lemos (2002), o interesse dos estudantes está intimamente ligado à aprendizagem escolar. Para os autores, sentir-se interessado é o objetivo da aprendizagem escolar. 
Entendendo o desinteresse como também desmotivação, é importante salientar que "estar motivado para aprender algo específico e concretizar eficazmente esse desejo é um processo complexo" (KRAPP; LEMOS, 2002, p. 78). Isto porque, segundo esse estudo, existem outros fatores que fortalecem ou enfraquecem a concretização do processo de aprendizagem, como o modo pelo qual a prática docente é exercida, as condições e situações individuais em que o estudante está inserido e as próprias possibilidades e limites de aprendizagem. Por isso, podemos compreender que o sentimento de motivação e o interesse escolar são fatores que apresentam significativa influência no processo de aprendizagem do estudante, uma vez que isso facilita a aquisição de conhecimentos, habilidades e experiências (SILVA, 2008).

É frequente, contudo, a responsabilização do estudante e do professor pelo interesse em estudar, como se fatores mais amplos não interferissem no processo de ensino e aprendizagem e no "sucesso/fracasso escolar", e, consequentemente, no desinteresse. Angelucci et al. (2004) ao realizarem o estado da arte das pesquisas sobre fracasso escolar, considerando o recorte temporal de 1991 a 2004, buscaram identificar, entre outros aspectos, as concepções de fracasso escolar, as quais foram assim definidas:

(a) O fracasso escolar como problema psíquico: a culpabilização das crianças e de seus pais; (b) O fracasso escolar como um problema técnico: a culpabilização do professor; (c) $O$ fracasso escolar como questão institucional: a lógica excludente da educação escolar e (d) $O$ fracasso escolar como questão política: cultura escolar, cultura popular e relações de poder (p. 60-62).

Pozzobon, Mahendra e Marin (2017), por sua vez, ao investigarem o sentido atribuído por alunos, pais e professores para a expressão "fracasso escolar", evidenciaram que estudantes o consideram como sinônimo de "desinteresse". Além disso, tanto os pais quanto os alunos admitem que fracasso e o desinteresse são reponsabilidades do próprio estudante. Já na ótica dos docentes participantes da pesquisa, há múltiplos fatores que desencadeiam o fracasso escolar, como características do indivíduo, questões familiares e sociais, escola e sociedade.

No que diz respeito ao papel do professor diante do desinteresse escolar, há, muitas vezes, a compreensão de que a desmotivação dos estudantes está única e diretamente relacionada com as metodologias adotadas pelos docentes. Sob essa perspectiva, caberia ao professor pensar estratégias de ensino para a superação do desinteresse. São inúmeras, inclusive, as pesquisas acadêmicas que reforçam essa ideia, ao justificarem a instituição e investigação de metodologias de ensino, nas diversas áreas do conhecimento, a partir da necessidade de superação do desinteresse dos estudantes. Obviamente esses estudos trazem importantes contribuições para se pensar propostas de ensino e são relevantes para a área de educação. Chamamos a atenção, contudo, para o papel que podem desempenhar diante da responsabilização docente acerca do desinteresse quando este é atrelado somente às escolhas metodológicas, deslocadas de discussões mais amplas sobre concepções educacionais, currículo e gestão escolar, por exemplo.

Silva (2016), entretanto, ao discutir os principais motivos relacionados à evasão escolar, argumenta, com base em Silva (2013), que o principal fator é a condição financeira das famílias e dos estudantes, colocando a pobreza como elemento-chave para o 
afastamento da escola. Nesse contexto, segundo o referido autor, o desinteresse seria uma consequência da falta de base educacional e de conteúdos do estudante. Ou seja, tanto o fracasso escolar quanto o desinteresse envolvem elementos para além do desenvolvimento cognitivo e psicológico do aprendiz e das escolhas metodológicas dos docentes. Esses apontamentos de Silva (2016), em nosso entendimento, estão relacionados também com a ampliação do acesso à educação escolar, promovida, principalmente, a partir da obrigatoriedade do Ensino Médio e da meta de universalização deste nível de ensino (BRASIL, 2009, 2010), uma vez que cada vez mais jovens e adolescentes passaram a frequentar a escola. Assim, o aumento do acesso à educação escolar, agora também pela população mais pobre, explica, em parte, a ampliação da discussão, no contexto da literatura, sobre a temática "Fracasso Escolar", especialmente a partir da década de 90.

Ampliando a discussão do desinteresse para além dos aspectos individuais do estudante e da atuação docente, Bazilio (2009) avalia o desinteresse como elemento estritamente relacionado com o modelo de gestão escolar. Para a autora, o enfrentamento do desinteresse se dá partir da introdução de uma gestão democrática, em que os pais e os demais membros que compõem a comunidade escolar possam participar ativamente das tomadas de decisão e resolução de problemas. O ponto de vista apresentado por Bazilio (2009) representa, a nosso ver, importante elemento na superação do desinteresse como forma de "culpabilização" de estudantes, professores, pais e escola. Diante disso, consideramos relevante mapear a produção recente, a partir do levantamento de teses e dissertações, para identificarmos como a temática vem sendo explorada no âmbito da pesquisa.

\section{CAMINHOS METODOLÓGICOS}

A presente pesquisa tem natureza qualitativa (LÜDKE; ANDRÉ, 1986) e configura uma revisão bibliográfica que teve como base de busca o catálogo de teses e dissertações da Capes. ${ }^{5}$ Abarca o recorte temporal de 2007 a 2018. Esse recorte temporal foi escolhido a partir do ano de criação do Fundo de Manutenção e Desenvolvimento da Educação Básica e de Valorização dos Profissionais da Educação (Fundeb), em 2007. ${ }^{6}$

Inicialmente realizou-se a busca no banco de dados usando-se o termo "desinteresse" como palavra-chave. Foram localizados 713 títulos. Os dados obtidos com essa primeira busca foram refinados a partir das seguintes ações:

(1) leitura de cada um dos títulos;

(2) identificação e exclusão dos trabalhos que não faziam nenhuma relação com educação/escola;

(3) identificação e exclusão dos trabalhos que faziam referência a aspectos específicos do Ensino Superior, sem relação com a formação de professores para a Educação Básica.

\footnotetext{
Para realizar a busca dos trabalhos acessamos o site https://catalogodeteses.capes.gov.br/catalogo-teses/\#!/ no dia 15/7/2019.

6 O presente estudo está atrelado a outros trabalhos de revisão de literatura envolvendo o financiamento da educação, por isso o recorte temporal levou em consideração o ano de criação do Fundeb.
} 
Foram selecionados, então, estudos que têm relação com: (a) a Educação Básica ou projetos sociais voltados para a inclusão de crianças e jovens que, de alguma forma, se articulam com a educação escolar; (b) práticas/atividades pedagógicas/metodologias de ensino nas diversas áreas do conhecimento; (d) o estabelecimento de articulações entre família e educação formal/escola; (e) a formação continuada de professores e os desafios da prática docente e $(f)$ o interesse pelo conhecimento e desenvolvimento de crianças e jovens. Selecionamos 324 títulos com esse primeiro refinamento.

Na sequência, um segundo refinamento da busca foi realizado e contemplou os seguintes encaminhamentos:

(1) Localização e cópia dos resumos dos trabalhos. ${ }^{7}$

(2) Leitura dos resumos.

(3) Classificação dos trabalhos quanto ao contexto de uso do termo "desinteresse": (a) como objeto central de pesquisa e discussão; (b) como argumento/ justificativa para a promoção/discussão de metodologias de ensino; (c) como aspecto apresentado enquanto resultado da investigação, cujo foco central estava relacionado com alguma temática que permeia a educação básica e (d) como expressão desvinculada de discussões acerca da educação escolar. ${ }^{8}$

Esse segundo refinamento resultou na seleção de 168 resumos, cujos focos estão, de algum modo, relacionados a entender o desinteresse escolar, seja como objeto central de investigação na identificação e discussão dos fatores que o desencadeiam, como justificativa e motivação para a proposição de estratégias de ensino, organizações curriculares e atividades variadas na comunidade escolar com vistas ao seu enfrentamento ou como elemento que interfere na atuação/formação docente.

Considerando esses diferentes enfoques para as investigações sobre o desinteresse escolar, identificados a partir da leitura dos resumos, os trabalhos foram organizados em dois grandes blocos, conforme Quadro 1.

Quadro 1 - Características e número de estudos em cada bloco.

\begin{tabular}{|l|c|}
\hline \multicolumn{1}{|c|}{ Blocos } & Número de trabalhos \\
\hline $\begin{array}{l}\text { Bloco 1: Estudos que têm como objetivo central discutir o } \\
\text { desinteresse escolar, os fatores relacionados a ele e suas implicações } \\
\text { na formação e atuação de professores. }\end{array}$ & 46 \\
\hline $\begin{array}{l}\text { Bloco 2: Estudos que apresentam e discutem estratégias/ } \\
\text { metodologias/ações para o enfrentamento do desinteresse escolar. }\end{array}$ & 122 \\
\hline
\end{tabular}

Fonte: Elaborado pelos autores.

\footnotetext{
14 resumos não foram localizados e, consequentemente, excluídos compulsoriamente da análise.

8 Alguns estudos, apesar de apresentarem relação explícita com o contexto educacional no título, usavam o termo "desinteresse" em outro contexto.
} 
Neste estudo serão apresentados os resultados provenientes da análise do primeiro bloco. A partir da leitura sistemática dos 46 resumos, e da identificação dos objetivos da pesquisa, buscou-se melhor compreender em que contexto o termo "desinteresse" era empregado pelos autores. Com isso, foi possível a definição de quatro categorias, quais sejam:

Categoria 1: desinteresse pela educação escolar: esses trabalhos envolvem o desinteresse pela área do conhecimento (subcategoria 1); pelo processo de aprendizagem (subcategoria 2) ou pelo desinteresse pela escola, de modo mais amplo (subcategoria 3).

Categoria 2: implicações do desinteresse do aluno na atividade docente: parte dos estudos apresenta o desinteresse dos estudantes como um fator que interfere na atuação docente.

Categoria 3: desinteresse como uma construção histórico-social; ligado a aspectos sociais: esta categoria engloba trabalhos que, de alguma forma, apresentam como a construção social e histórica influencia o desinteresse escolar de crianças e jovens.

Categoria 4: desinteresse associado à indisciplina, abandono, evasão e desempenho escolar: há estudos que buscam discutir os diversos fatores relacionados com o desinteresse dos estudantes pela escola.

Os resultados da análise dos resumos serão apresentados, na sequência, a partir dessas quatro categorias emergentes. Reconhece-se, no entanto, conforme argumente Ferreira (2002) ao discutir a metodologia de pesquisa denominada "Estado da Arte", ${ }^{\prime \prime}$ que pode haver limitações na análise em razão de a mesma ser oriunda somente dos resumos e não da leitura integral dos trabalhos. No caso deste estudo, entretanto, tomou-se o cuidado de identificar que elementos analíticos poderiam ser obtidos somente com a leitura dos resumos, não havendo intenção de se propor inferências que ultrapassem essa limitação.

\section{APRESENTAÇÃO E DISCUSSÃO DOS RESULTADOS}

Neste tópico serão expostas as principais discussões enfocadas nos estudos, sintetizadas de acordo com a categoria referente. Os trabalhos também foram codificados e apresentados por ordem cronológica. O primeiro número representa a categoria e o segundo representa a ordem numérica. Assim, o código "01.01" diz que o trabalho é pertencente à primeira categoria e é o primeiro trabalho desta. Se houver subcategoria, o código é "01.a. 01", que significa: primeira categoria, subcategoria "a" e primeiro trabalho da subcategoria "a".

\section{Categoria 1: Desinteresse pela educação escolar}

Esta categoria engloba trabalhos que, de alguma maneira, sinalizaram a possível relação existente entre o desinteresse escolar do estudante com o desinteresse pela educação escolar como um todo, de uma maneira que tira o foco de que o desinte-

Considera-se que o presente estudo não se enquadra em "Estado da Arte" (FERREIRA, 2002). 
resse escolar seria um problema unicamente do estudante e trazem reflexões de que isso pode ser resultante de uma série de questões relacionadas com o conhecimento escolar, a sala de aula e/ou escola. Assim, a compreensão que se tem é de que quando o estudante mostra não estar interessado, pode ser que esse sentimento esteja relacionado ao desinteresse pela área do conhecimento (subcategoria 1); pelo processo de aprendizagem (subcategoria 2 ) ou pelo desinteresse pela escola, de modo mais amplo (subcategoria 3).

\section{A Desinteresse pela área do conhecimento}

Estes estudos evidenciaram a questão do desinteresse associada a uma determinada área do conhecimento, mais precisamente por Educação Física (3); por Matemática (2); por Filosofia (2); por Física (2) por Ciências (1); por Contabilidade (1) e por Língua Inglesa (1). Quatorze trabalhos compuseram esta subcategoria, como melhor apresentados no Quadro 2.

Quadro 2 - Relação de estudos analisados na subcategoria desinteresse pela área do conhecimento

\begin{tabular}{|c|c|}
\hline Código & Teses e Dissertação por autor e fonte \\
\hline 01.a.01 & $\begin{array}{l}\text { NETO, L. C. B. Os interesses e posturas de jovens alunos frente às ciências: resultados do } \\
\text { Projeto ROSE aplicado no Brasil. São Paulo: USP, 2008. (Tese de Doutorado). } \\
\text { Link: https://roseproject.no/network/countries/brazil/bra-caldeira-tolentino-neto.pdf }\end{array}$ \\
\hline 01.a.02 & $\begin{array}{l}\text { SOUZA, Z. F. Representações de alunos sobre ensinar-aprender inglês e seu (des)interesse } \\
\text { em estudar essa língua. São Paulo: Pontifícia Universidade Católica de São Paulo, } 2009 . \\
\text { (Dissertação de Mestrado). } \\
\text { Link: http://bdtd.ibict.br/vufind/Record/PUC_SP-1_d13aceb367497bf48f8da53e1d7a57d8 }\end{array}$ \\
\hline 01.a.03 & $\begin{array}{l}\text { SANTOS, C. F. Os desafios do ensino de filosofia na sociedade atual. São Paulo: Universidade } \\
\text { Nove de Julho, 2009. (Dissertação de Mestrado). } \\
\text { Link: https://bibliotecatede.uninove.br/handle/tede/400 }\end{array}$ \\
\hline 01.a.04 & $\begin{array}{l}\text { ALMEIDA, F. F. L. Um olhar para a questão do aparente desinteresse pelo ensino-aprendizagem } \\
\text { de língua inglesa por alunos da escola pública. São Paulo: Pontifícia Universidade Católica de } \\
\text { São Paulo, 2012. (Dissertação de Mestrado). } \\
\text { Link: https://sapientia.pucsp.br/handle/handle/13562 }\end{array}$ \\
\hline 01.a.05 & $\begin{array}{l}\text { OLIVEIRA, I. M. A filosofia no Ensino Médio: realidade e desafios nas escolas públicas da } \\
\text { região de Araranguá-SC. Florianópolis: UFSC, } 2013 \text { (Dissertação de Mestrado). } \\
\text { Link: https://ope.education/a-filosofia-no-ensino-medio-realidade-e-desafios-nas-escolas- } \\
\text { publicas-da-regiao-de-ararangua-sc/ }\end{array}$ \\
\hline 01.a.06 & $\begin{array}{l}\text { BARBOSA, A. S. M. Análise do ensino de física no Ensino Médio: um estudo de caso. Fortaleza: } \\
\text { Universidade Federal do Ceará, Fortaleza, } 2014 \text {. (Dissertação de Mestrado). } \\
\text { Link: http://www.repositorio.ufc.br/handle/riufc/8263 }\end{array}$ \\
\hline 01.a.07 & $\begin{array}{l}\text { ROCHA, C. C. S. Análise do baixo desempenho em matemática dos alunos do 6o ano do } \\
\text { Ensino Fundamental da Escola Estadual Getúlio Vargas (Belo Horizonte-MG). Juiz de Fora: } \\
\text { Universidade Federal de Juiz de Fora, 2014. (Dissertação de Mestrado). } \\
\text { Link: http://www.mestrado.caedufjf.net/analise-do-baixo-desempenho-em-matematica- } \\
\text { dos-alunos-do-6o-ano-do-ensino-fundamental-da-escola-estadual-getulio-vargas-belo- } \\
\text { horizonte-mg/ }\end{array}$ \\
\hline 01.a.08 & $\begin{array}{l}\text { LIMA, J. S. Concepções e percepções de uma professora de Matemática e de seus alunos no } \\
\text { 6o ano do Ensino Fundamental sobre indisciplina. Passo Fundo: Universidade de Passo Fundo, } \\
\text { 2015. (Tese de Doutorado). } \\
\text { Link: http://tede.upf.br/jspui/handle/tede/599 }\end{array}$ \\
\hline
\end{tabular}




\begin{tabular}{|c|c|}
\hline 01.a.09 & $\begin{array}{l}\text { CESARO, H. L. Abandono discente nas aulas de Educação Física do Ensino Médio: uma } \\
\text { etnografia escolar na rede estadual do meio-oeste catarinense. Porto Alegre: Universidade } \\
\text { Federal do Rio Grande do Sul, 2016. (Tese de Doutorado). } \\
\text { Link: https://lume.ufrgs.br/bitstream/handle/10183/159121/001022445. } \\
\text { pdf?sequence=1\&isAllowed=y }\end{array}$ \\
\hline 01.a.10 & $\begin{array}{l}\text { FRANKIY, M. A. O (des)interesse dos estudantes do Ensino Médio integrado em uma Instituição } \\
\text { Federal de ensino. Curitiba: Universidade do Paraná, 2016. (Dissertação de Mestrado). } \\
\text { Link: https://acervodigital.ufpr.br/bitstream/handle/1884/44107/R\%20-\%20D\%20-\%20 } \\
\text { MARIANNA\%20ANGONESE\%20FRANKIV.pdf?sequence=3 }\end{array}$ \\
\hline 01.a.11 & $\begin{array}{l}\text { KRUMMENAUER, W. L. O desinteresse pela Física na região do Vale do Rio dos Sinos: suas } \\
\text { causas e consequências na educação de jovens e adultos. Porto Alegre: Universidade Federal } \\
\text { do Rio Grande do Sul, 2016. (Dissertação de Mestrado). } \\
\text { Link: https://www.lume.ufrgs.br/handle/10183/147881 }\end{array}$ \\
\hline 01.a.12 & $\begin{array}{l}\text { MATTOS, S. M. N. O sentido da matemática ou a matemática do sentido: um estudo com } \\
\text { alunos do Ensino Fundamental II. São Paulo: Pontifícia Universidade Católica de São Paulo, } \\
\text { 2016. (Tese de Doutorado). } \\
\text { Link: https://sapientia.pucsp.br/handle/handle/18975 }\end{array}$ \\
\hline 01.a.13 & $\begin{array}{l}\text { SOUZA, D. A. Aderência e motivação dos adolescentes de Ensino Médio nas aulas de Educação } \\
\text { Física escolar. São Paulo: Universidade Cruzeiro do Sul, 2018. (Dissertação de Mestrado). } \\
\text { Link:https://sucupira.capes.gov.br/sucupira/public/consultas/coleta/trabalhoConclusao/ } \\
\text { viewTrabalhoConclusao.jsf?popup=true\&id_trabalho=7026857 }\end{array}$ \\
\hline 01.a.14 & $\begin{array}{l}\text { ANISZEWSKI, E. O desinteresse discente pelas aulas de Educação Física no Ensino Fundamental: } \\
\text { análise sob a perspectiva das necessidades psicológicas básicas. Rio de Janeiro: UFRRJ, } 2018 . \\
\text { (Dissertação de Mestrado). } \\
\text { Link:https://www.academia.edu/36552041/O_DESINTERESSE_DISCENTE_PELAS_ } \\
\text { AULAS_DE_EDUCA\%C3\%87\%C3\%830_F\%C3\%8DSICA_NO_ENSINO_FUNDAMENTAL_ } \\
\text { an\%C3\%A1lise_sob_a_perspectiva_das_necessidades_psicol\%C3\%B3gicas_b\%C3\%A1sicas }\end{array}$ \\
\hline
\end{tabular}

Fonte: Elaborado pelos autores.

Por meio da leitura dos resumos concluímos que os dados obtidos pelos autores, em geral, contribuíram para identificar de que forma os sujeitos davam sentido ao desinteresse e as razões que atribuem para este fenômeno.

Das razões para o desinteresse, as que merecem maior destaque são a relação professor-aluno e as práticas pedagógicas exercidas pelo docente. Em todos os trabaIhos foi apontado que a não realização de atividades experimentais, integrativas e ativas afetam o interesse do estudante pela disciplina. Também foi constatado que a relação professor-aluno é uma carga afetiva complexa que influencia no processo de aprendizagem. Ainda, a dificuldade na apreensão dos conteúdos das disciplinas foi destacada como um grande fator para o desinteresse.

A respeito dessas reflexões e baseando-nos na associação entre desinteresse e aprendizagem temos uma vasta literatura que aponta, a partir de diversos prismas teóricos, sobretudo da área da Psicologia, sobre a motivação para a aprender/estudar e como ela pode ser facilitada pelos professores. Nesse contexto Rego (2003) sinaliza, a partir da perspectiva histórico-cultural, o quanto a escola e os processos de aprendizagem que ali se inserem são importantes para que os sujeitos processem seu desenvolvimento global, mediante as atividades programadas e realizadas em sala de aula e fora dela. De forma semelhante, Santos (2013) acrescenta que o professor, para auxiliar no processo ensino-aprendizagem, deve exercer um papel de mediador, estimulando, ajudando os estudantes a se organizarem e educar por meio do ensino. 
Pensando, no entanto, sobre estes resultados e sobre o que nos traz a literatura, questionamos, em primeiro lugar, sobre o enfoque e responsabilidade atribuídos ao professor para manter o interesse dos estudantes. Apenas uma "boa mediação" conseguiria "fazer aprender"? Seria só responsabilidade do professor o desinteresse escolar? Quem são os outros responsáveis por isso? Também analisamos que cultural e socialmente certas disciplinas, a exemplo de Matemática, foram entendidas como "difíceis" de serem apreendidas.

\section{B Desinteresse e processo de aprendizagem}

De maneira geral, as pesquisas que compõem esta subcategoria revelaram que o desinteresse escolar está associado à forma como o conteúdo é explicado e pela maneira como se estabelece o processo de aprendizagem entre professor-aluno. Dos resultados obtidos pela revisão, seis trabalhos investigam e discutem o desinteresse de crianças e jovens pelo processo de aprendizagem.

Quadro 3 - Relação de estudos analisados na subcategoria desinteresse e processo de aprendizagem

\begin{tabular}{|c|c|}
\hline Código & Teses e Dissertação por autor e fonte \\
\hline 01 & $\begin{array}{l}\text { RESQUETTI, S. O. Como se movem os projéteis nos livros didáticos de física e no vestibular? } \\
\text { Inquirindo o Galileu sintético de hoje. Maringá: Universidade Estadual de Maringá, } 2007 . \\
\text { (Dissertação de Mestrado). } \\
\text { Link: http://nou-rau.uem.br/nou-rau/document/?code=vtls000164873 }\end{array}$ \\
\hline 01.b.02 & $\begin{array}{l}\text { WERLANG, L. M. S. Discurso e sujeito: a representação do ensino público nos textos de alunos } \\
\text { de ensino médio. Taubaté: Universidade de Taubaté, 2008. (Dissertação de Mestrado). } \\
\text { Link: http://livros01.livrosgratis.com.br/cp073868.pdf }\end{array}$ \\
\hline 01.b.03 & $\begin{array}{l}\text { MENEZES, E. M. P. L. Ensino de leitura e escrita: entre reclamações e apoio pedagógico. Cuiabá: } \\
\text { Universidade Federal de Mato Grosso, 2010. (Dissertação de Mestrado). } \\
\text { Link: http://livros01.livrosgratis.com.br/cp129887.pdf }\end{array}$ \\
\hline 01.b.04 & $\begin{array}{l}\text { BAU, L. B. A indisciplina e o processo de ensino-aprendizagem: um estudo no Ensino } \\
\text { Fundamental. Presidente Prudente: Universidade do Oeste Paulista, 2011. (Dissertação de } \\
\text { Mestrado). } \\
\text { Link: http://bdtd.ibict.br/vufind/Record/UOES_0c8aa8047133358d339dae8fb8d304e3 }\end{array}$ \\
\hline 01.b.05 & $\begin{array}{l}\text { COSTA, G. G. S. O que toca essa geração touch? - Uma reflexão hipertextual sobre as novas } \\
\text { práticas de leitura e escrita na era digital. Rio de Janeiro: Pontifícia Universidade Católica do } \\
\text { Rio de Janeiro, } 2014 \text { (Dissertação de Mestrado). } \\
\text { Link:https://sucupira.capes.gov.br/sucupira/public/consultas/coleta/trabalhoConclusao/ } \\
\text { viewTrabalhoConclusao.jsf?popup=true\&id_trabalho=1152339 }\end{array}$ \\
\hline 01.b.06 & $\begin{array}{l}\text { COSTA, C. G. Ensino de Literatura na Escola Estadual José Ferreira da Costa - Costa Rica, MS: } \\
\text { práticas, desafios e perspectivas. Dourados: Universidade Estadual de Mato Grosso do Sul, } \\
\text { 2016. (Dissertação de Mestrado). } \\
\text { Link:https://sucupira.capes.gov.br/sucupira/public/consultas/coleta/trabalhoConclusao/ } \\
\text { viewTrabalhoConclusao.jsf?popup=true\&id_trabalho=3747154 }\end{array}$ \\
\hline
\end{tabular}

Fonte: Elaborado pelos autores.

Como trazido pela pesquisa: "A indisciplina e o processo de ensino aprendizagem: um estudo no ensino fundamental" (01.b.04), o desinteresse escolar também está associado ao baixo desempenho acadêmico dos estudantes, que também é influenciado pela falta de disciplina durante a realização do trabalho pedagógico, a falta de respon- 
sabilidade com os afazeres escolares, o desinteresse pelo conteúdo ensinado na sala de aula, a dificuldade no andamento pedagógico das aulas proposto pelo professor, bem como a estrutura dos currículos escolares e a postura do docente em sala de aula.

Outro ponto que merece destaque nesta discussão refere-se à transformação nos modos de circulação do saber contemporâneo. Como sinalizado pelo trabalho "O que toca essa geração touch? Uma reflexão hipertextual sobre as novas práticas de leitura e escrita na era digital" (01.b.05), é preciso atenção à pluralidade de saberes em que estamos inseridos, pois isso impacta e constrói novos modos de aprender, como também a forma como a metodologia deve ser empregada para melhorar a relação de ensino-aprendizagem.

Sobre isso, fazemos um adendo baseando-nos nas reflexões de Silva, Fernandes e Silva (2017) em seu artigo intitulado "Afinal, o que é, no contemporâneo, uma sala de aula?". Nele os autores argumentam que não podemos negligenciar os avanços tecnológicos que obtemos ao longo das décadas, por isso é necessário ratificar a articulação entre os dispositivos digitais no processo de ensino-aprendizagem. Os pesquisadores também apontaram que, cada vez mais, não faz sentido estabelecermos qualquer tipo de dicotomia entre os espaços off-line e on-line, pois precisamos entender que nossa sociedade contemporânea já está imersa em uma rede tecnológica.

Por fim, a partir da leitura dos resumos destes seis trabalhos, concluímos que para essas pesquisas o processo de aprendizagem parece influenciar no interesse dos estudantes. Em razão disso, enfatizamos sobre o quão importante é apresentar os conteúdos em sala de aula utilizando referências socioculturais relativas aos processos de vida dos alunos, para que a construção de sentidos e aprendizagem ocorra. Isso envolve, contudo, em nossa percepção, a proposição de uma educação dialógica e problematizadora (FREIRE, 1987), em que o estudante seja considerado como sujeito do conhecimento (DELIZOICOV; ANGOTTI; PERNAMBUCO, 2007) e protagonista de sua história. Ou seja, repensar a forma como os conteúdos são apresentados em sala de aula para o enfrentamento do desinteresse, nesta perspectiva, não é responsabilidade única do professor, mas tem relação com um projeto educacional mais amplo.

\section{C Desinteresse pela escola}

Esta subcategoria engloba trabalhos que trazem a reflexão de que a falta de interesse escolar possível de ser identificada, pode estar relacionada com a falta de interesse na forma como a educação escolar é apresentada aos estudantes. Assim, dois trabalhos fazem parte desta categoria.

Quadro 4 - Relação de estudos analisados na categoria desinteresse pela educação escolar

\begin{tabular}{|c|c|}
\hline Código & Teses e Dissertação por autor e fonte \\
\hline 01.c.01 & $\begin{array}{l}\text { SILVA, A. C. C. A relação dos jovens com a cultura escolar e os sentidos da escola para } \\
\text { estudantes de uma classe de correção de fluxo escolar. Recife: Universidade de Pernambuco, } \\
\text { 2016. (Dissertação de Mestrado). } \\
\text { Link: } \\
\text { https://sucupira.capes.gov.br/sucupira/public/consultas/coleta/trabalhoConclusao/ } \\
\text { viewTrabalhoConclusao.jsf?popup=true\&id_trabalho=3758865 }\end{array}$ \\
\hline
\end{tabular}


01.c.02 1 BONOTTO, M. R. D. S. As percepções e os significados de escola para os estudantes adolescentes: um estudo de caso no Instituto Federal Farroupilha. Santa Maria: Universidade Franciscana, 2018. (Dissertação de Mestrado).

Link: http://tede.universidadefranciscana.edu.br:8080/handle/UFN-BDTD/666

Fonte: Elaborado pelos autores.

A partir da leitura e análise dos resumos destes estudos, foi possível constatar, em primeiro lugar, que os estudantes que participaram de ambas as pesquisas dão sentido positivo à escola. Em um dos trabalhos eles consideram a escola como lugar de viver o presente e se preparar para o futuro; lugar de qualidade; lugar de disciplinamento e lugar de adquirir conhecimentos (01.c.01). E, em outro estudo (01.c.02), os participantes do grupo focal da pesquisa apontaram que a escola possui muita importância e significado para eles, principalmente pelos vínculos interpessoais construídos, pelo conhecimento e pela possibilidade de um futuro melhor.

Identificou-se, no entanto, que o desinteresse pela escola ou o pouco investimento por parte dos estudantes jovens em seus processos de escolarização decorre, em muitos casos, da insatisfação e da ausência de sentidos diante das práticas, espaços, tempos e objetos escolares que configuram a cultura escolar (01.c.01). Como também os estudantes rejeitam a metodologia expositiva e gostam de aulas que proporcionam a participação ativa, e para tanto, destacaram metodologias como aulas práticas, jogos, músicas, viagens de estudo, vídeos, séries, como recursos, que de acordo com eles, se aprende melhor (01.c.02).

Estas inferências, a saber, auxiliam-nos a pensar sobre o currículo e as metodologias comumente empregadas em ambiente escolar. Será que a forma pela qual ensinamos é atraente para os estudantes? Fazem eles sentirem-se interessados pelos conteúdos a serem aprendidos? Destacamos a importância de pesquisas que enfoquem questões curriculares e metodológicas, pois o interesse em se estudar parece estar inserido em uma complexidade que também engloba a forma como concebemos o espaço, os tempos e os currículos escolares.

Por fim, chamamos a atenção para o fato de que esta categoria, e suas subcategorias, abarcam 22 dos estudos localizados com a revisão, o que representa cerca de $48 \%$ do corpus de análise. Os elementos destacados a partir dos resumos dos estudos parecem indicar uma intrínseca relação, principalmente, entre o desinteresse escolar e a responsabilização de professores, uma vez que todas as subcategorias evidenciam aspectos relacionados com escolhas metodológicas. Resta, contudo, analisar de forma mais profunda as discussões abordadas nos trabalhos para que possamos melhor compreender como enfocam essa questão.

\section{Categoria 2 - Implicações do desinteresse do aluno na atividade docente}

Esta categoria engloba trabalhos que enfatizam, de alguma forma, implicações do desinteresse do aluno na atividade docente. Ao todo, dez trabalhos, relacionados no Quadro 5, fazem parte dessa categoria: 
Quadro 5 - Relação de estudos analisados na categoria implicações do desinteresse do aluno na atividade docente

\begin{tabular}{|c|c|}
\hline Código & Teses e Dissertação por autor e fonte \\
\hline 02.01 & $\begin{array}{l}\text { MELO, S. C. A ressignificação da prática pedagógica do professor egresso do PDE-PR. } \\
\text { Campo Mourão: Universidade Federal de Paraná, 2016. (Dissertação de Mestrado). } \\
\text { Link: http://ppgsed.unespar.edu.br/arquivos/sergio_mello_final_09-05_2016.pdf }\end{array}$ \\
\hline 02.02 & $\begin{array}{l}\text { PAPARELLI, R. Desgaste mental do professor da rede pública de ensino. Trabalho sem sentido } \\
\text { sob a política de regularização do fluxo escolar. São Paulo: Universidade de São Paulo, } 2009 . \\
\text { (Tese de Doutorado). } \\
\text { Link: http://www.teses.usp.br/teses/disponiveis/47/47134/tde-07122009-145916/pt-br. } \\
\text { php }\end{array}$ \\
\hline 02.03 & $\begin{array}{l}\text { SILVA, I. F. Sofrimento psíquico e mal-estar docente: uma interface com o trabalho, a saúde } \\
\text { e a família. Salvador: Universidade Católica de Salvador, 2013. (Dissertação de Mestrado). } \\
\text { Link: https://sucupira.capes.gov.br/sucupira/public/consultas/coleta/trabalhoConclusao/ } \\
\text { viewTrabalhoConclusao.jsf?popup=true\&id_trabalho=151269 }\end{array}$ \\
\hline 02.04 & $\begin{array}{l}\text { MENDES, C. M. L. Magistério: vocação ou sofrimento? Percepções de professores acerca } \\
\text { do cotidiano escolar num contexto de precarização e intensificação do trabalho docente. } \\
\text { Ribeirão Preto: Centro Universitário Moura Lacerda, 2009. (Dissertação de Mestrado). } \\
\text { Link: } \\
\text { http://www.dominiopublico.gov.br/pesquisa/DetalheObraForm.do?select_action=\&co_- } \\
\text { obra=164516 }\end{array}$ \\
\hline 02.05 & $\begin{array}{l}\text { CARVALHO, E. M. S. Reflexões sobre a resistência à prática docente de língua inglesa no } \\
\text { interior da Bahia. São Paulo: Pontifícia Universidade Católica de São Paulo, 2010. (Dissertação } \\
\text { de Mestrado). Link: } \\
\text { https://tede2.pucsp.br/handle/handle/14140 }\end{array}$ \\
\hline 02.06 & $\begin{array}{l}\text { LIMA, E. C. Os sentimentos do professor gerados pelas suas vivências na prática docente: um } \\
\text { estudo com docentes em uma escola pública no Piauí. Fortaleza: Universidade de Fortaleza, } \\
2011 \text { (Dissertação de Mestrado). } \\
\text { Link: http://bdtd.ibict.br/vufind/Record/UFOR_244ff8dc8538459f771ec45bc25a55a5 }\end{array}$ \\
\hline 02.07 & $\begin{array}{l}\text { TONIN, E. C. Formação na descontinuidade: um estudo sobre a formação continuada } \\
\text { de professores em Araçoiaba da Serra/SP. Sorocaba: Universidade de Sorocaba, } 2013 . \\
\text { (Dissertação de Mestrado). } \\
\text { Link: https://sucupira.capes.gov.br/sucupira/public/consultas/coleta/trabalhoConclusao/ } \\
\text { viewTrabalhoConclusao.jsf?popup=true\&id_trabalho=974649 }\end{array}$ \\
\hline 02.08 & $\begin{array}{l}\text { SOUZA, D. L. G. A questão da leitura na formação contínua de professores de língua } \\
\text { portuguesa: o que leem, o que discutem. Cuiabá: Universidade Federal de Mato Grosso, } \\
\text { 2013. (Dissertação de Mestrado). } \\
\text { Link: https://sucupira.capes.gov.br/sucupira/public/consultas/coleta/trabalhoConclusao/ } \\
\text { viewTrabalhoConclusao.jsf?popup=true\&id_trabalho=105387 }\end{array}$ \\
\hline 02.09 & $\begin{array}{l}\text { BARROS, C. M. F. A formação pedagógica dos professores iniciantes do Instituto Federal } \\
\text { Sul-rio-grandense: intencionalidade, necessidade ou desinteresse. Pelotas: Universidade } \\
\text { Federal de Pelotas, 2017. (Tese de Doutorado). } \\
\text { Link: https://sucupira.capes.gov.br/sucupira/public/consultas/coleta/trabalhoConclusao/ } \\
\text { viewTrabalhoConclusao.jsf?popup=true\&id_trabalho }=5744858\end{array}$ \\
\hline 02.10 & $\begin{array}{l}\text { VOLTERO, K. M. Os conflitos de uma professora de língua portuguesa em início de carreira } \\
\text { pública reconfigurados em duas entrevistas. São José do Rio Preto: Universidade Estadual } \\
\text { Paulista Júlio de Mesquita Filho, 2018. (Dissertação de Mestrado). } \\
\text { Link: https://sucupira.capes.gov.br/sucupira/public/consultas/coleta/trabalhoConclusao/ } \\
\text { viewTrabalhoConclusao.jsf?popup=true\&id_trabalho=6378395 }\end{array}$ \\
\hline
\end{tabular}

Fonte: Elaborado pelos autores. 
Por meio da leitura dos resumos dos trabalhos foi possível perceber que o desinteresse dos estudantes impacta a carreira docente de forma muito negativa. Tal como aponta a dissertação 02.03, de título "Sofrimento Psíquico e mal-estar docente: uma interface com o trabalho, a saúde e a família" - que utilizou como metodologia de pesquisa entrevistas com profissionais da rede municipal do Estado paulistano - o desinteresse por parte do corpo discente tem contribuído sobremaneira para a intensificação do trabalho docente e reforçado a situação de proletarização, causando uma crise profunda na profissão.

O desinteresse escolar também é apontado, nos trabalhos analisados, como um fator que afeta a saúde mental dos docentes. De acordo com a dissertação 02.06, de título "Os sentimentos do professor gerados pelas suas vivências na prática docente: um estudo com docentes em uma escola pública no Piaui'", a falta de interesse dos estudantes foi identificada como geradora de sentimento de desconforto, estresse, mal-estar, insatisfação e até sofrimento psíquico, conforme resultados de entrevistas com cinco professores de uma escola pública do município de Água Branca, Piauí.

Os trabalhos evidenciam, ainda, a possível relação entre o desinteresse escolar e o interesse dos profissionais pela formação continuada. Segundo o trabalho de título " $A$ Formação pedagógica dos professores iniciantes do Instituto Federal Sul-rio-grandense: Intencionalidade, necessidade ou desinteresse" (02.09), o interesse em continuar e investir na carreira é influenciado pelas situações cotidianas que vivenciam. Quando, por exemplo, há situações de indisciplina e desinteresse escolar, isso afeta o interesse no investimento de formação da própria carreira. De forma semelhante, o desinteresse foi apontado como um dos fatores que auxiliam para que os egressos de cursos de Graduação de Letras percam o interesse em atuar como docente.

Assim, a partir da análise dos trabalhos dessa categoria, é possível sinalizar que o desinteresse de professores e o desinteresse de estudantes apresentam algum nível de relação, uma vez que tanto estudantes se sentem desinteressados em razão das escoIhas metodológicas dos docentes quanto professores sentem-se desmotivados a inovar em sala de aula e estudar por conta do desinteresse dos alunos. Isso também é evidenciado por Silva (2012) e Barreiros (2008), que ao investigarem a desmotivação de professores em sala de aula, argumentam que tanto o desinteresse dos estudantes quanto das famílias acaba interferindo na atuação do professor, assim como outros fatores, a exemplo de violência, baixa remuneração e desvalorização do governo e da sociedade. Nesse contexto, Oliveira (2009, p. 81) destaca como alternativa, ao discutir as implicações do desinteresse do estudante na prática do professor, "a necessidade cada vez mais da participação do aluno até mesmo na escolha de conteúdos", sob a perspectiva da pedagogia de projetos.

\section{Categoria 3 - Desinteresse como uma construção histórico-social ligado a aspectos sociais}

Estes trabalhos referem-se a estudos em que o desinteresse escolar é entendido como uma construção social e histórica diretamente influenciada pelas condições sociais em que as crianças e jovens estão imersos. Os estudantes, pelos trabalhos, são 
compreendidos como sujeitos constituídos social e historicamente, portanto o desinteresse que pode provir deles é resultante de um conjunto de aspectos sociais e culturais. Quatro trabalhos compõem esta categoria, conforme exposto no Quadro 6:

Quadro 6 - Relação de estudos analisados na categoria desinteresse como uma construção histórico-social, ligados a aspectos sociais

\begin{tabular}{|c|l|}
\hline Código & \multicolumn{1}{|c|}{ Teses e Dissertação por autor e fonte } \\
\hline 03.01 & $\begin{array}{l}\text { SILVA, C. A. A. Indústria cultural, educação escolar e currículo: a contradição ocultada e o } \\
\text { desinteresse dos alunos pela educação formal. São Paulo: Pontifícia Universidade Católica } \\
\text { de São Paulo, 2010. (Dissertação de Mestrado). } \\
\text { Link: https://tede.pucsp.br/handle/handle/10203 }\end{array}$ \\
\hline 03.02 & $\begin{array}{l}\text { REIS, R. R. Juventude e conhecimento escolar: um estudo sobre o (des)interesse. São Paulo: } \\
\text { Pontifícia Universidade Católica de São Paulo, 2014. (Tese de doutorado). } \\
\text { Link: } \\
\text { https://www.capes.gov.br/images/stories/download/pct/mencoeshonrosas/227789.pdf }\end{array}$ \\
\hline 03.03 & $\begin{array}{l}\text { BRANCO, M. F. F. C. Violências escolares: falas de educadores. Recife: Universidade Católica } \\
\text { de Pernambuco, 2014. (Tese de Doutorado). } \\
\text { Link: } \\
\text { https://sucupira.capes.gov.br/sucupira/public/consultas/coleta/trabalhoConclusao/ } \\
\text { viewTrabalhoConclusao.jsf?popup=true\&id_trabalho=1861150 }\end{array}$ \\
\hline 03.04 & $\begin{array}{l}\text { MENEZ, I. C. S. B. Adolescentes de comunidades vulneráveis: a presença da efetiva inclusão } \\
\text { educacional em suas vidas. Brasília: Universidade Católica de Brasília, 2018. (Dissertação de } \\
\text { Mestrado). } \\
\text { Link: https://sucupira.capes.gov.br/sucupira/public/consultas/coleta/trabalhoConclusao/ } \\
\text { viewTrabalhoConclusao.jsf?popup=true\&id_trabalho=6663706 }\end{array}$ \\
\hline
\end{tabular}

Fonte: Elaborado pelos autores.

Segundo o resumo da dissertação 03.01, a falta de interesse escolar pode estar associada à frustração do estudante de não ter uma boa qualidade de ensino. De acordo com o trabalho 03.02, a falta de interesse é observável quando objetivado na sala de aula em comportamentos tais como: recusa a realizar atividades relacionadas à leitura, escrita e análise de qualquer conteúdo; violência contra professores, prédios escolares e seus próprios colegas; indisciplina e despreocupação com notas baixas.

Podemos concluir, portanto, por intermédio da análise dos resumos dos trabalhos desta categoria, que a falta de interesse dos estudantes parece estar sustentada por barreiras sociais e culturais enfrentadas diariamente pelos sujeitos, fatores que segundo o resumo da dissertação 03.04, seriam: desemprego, analfabetismo, inexistência de assistências básicas, entre outros.

\section{Categoria 4 - Desinteresse associado à indisciplina, abandono, evasão e desempenho escolar}

Estes trabalhos trouxeram a temática do desinteresse intrinsecamente associada à indisciplina, abandono, evasão e desempenho escolar. Dez trabalhos, relacionados no Quadro 7, compõem esta categoria: 
Quadro 7 - Relação de estudos analisados na categoria desinteresse associado à indisciplina, abandono, evasão e desempenho escolar

\begin{tabular}{|c|c|}
\hline Código & Teses e Dissertação por autor e fonte \\
\hline 04.01 & $\begin{array}{l}\text { BELÉM, R. C. Representações sociais sobre indisciplina escolar no ensino médio. Recife } \\
\text { Universidade Federal de Pernambuco, 2008. (Dissertação de Mestrado). } \\
\text { Link: https://repositorio.ufpe.br/handle/123456789/8182 }\end{array}$ \\
\hline 04.02 & $\begin{array}{l}\text { VIEIRA, A. S. Representações sociais de jovens-alunos de uma escola ribeirinha sobre } \\
\text { exploração sexual juvenil e as implicações nas suas escolarizações. Belém: Universidade } \\
\text { Federal do Pará, 2011. (Dissertação de Mestrado). } \\
\text { Link: http://ppgedufpa.com.br/bv/arquivos/File/andreea_mest2011_pdf.pdf }\end{array}$ \\
\hline 04.03 & $\begin{array}{l}\text { SHIRASU, M. R. Determinantes da evasão e repetência escolar. Fortaleza: Universidade } \\
\text { Federal do Ceará, 2014. (Dissertação de Mestrado). } \\
\text { Link: https://sucupira.capes.gov.br/sucupira/public/consultas/coleta/ } \\
\text { trabalhoConclusao/viewTrabalhoConclusao.jsf?popup=true\&id_trabalho=887794 }\end{array}$ \\
\hline 04.04 & $\begin{array}{l}\text { NOVAIS, L. F. Educação profissional: uma análise sobre a evasão e a permanência no curso } \\
\text { Técnico em Agropecuária Integrado ao Ensino Médio no Instituto Federal de Rondônia - } \\
\text { Campus Colorado do Oeste. Rio de Janeiro: Universidade Federal Rural do Rio de Janeiro, } \\
\text { 2014. (Dissertação de Mestrado). } \\
\text { Link: https://sucupira.capes.gov.br/sucupira/public/consultas/coleta/ } \\
\text { trabalhoConclusao/viewTrabalhoConclusao.jsf?popup=true\&id_trabalho=1898136 }\end{array}$ \\
\hline 04.05 & $\begin{array}{l}\text { OLIVEIRA, L. C. Evasão escolar: identificando causas e propondo intervenções. São } \\
\text { Leopoldo: Escola Superior de Teologia, 2016. (Dissertação de Mestrado). } \\
\text { Link: https://sucupira.capes.gov.br/sucupira/public/consultas/coleta/ } \\
\text { trabalhoConclusao/viewTrabalhoConclusao.jsf?popup=true\&id_trabalho=3966567 }\end{array}$ \\
\hline 04.06 & $\begin{array}{l}\text { DITTERBERNER, I. N. M. (Des)motivação dos estudantes adolescentes em relação ao ensino } \\
\text { formal: estudo de caso de uma turma do } 8 \text { o ano da rede pública municipal de Monte } \\
\text { Mor - SP. São Paulo: Centro Universitário Salesiano de São Paulo, 2016. (Dissertação de } \\
\text { Mestrado). } \\
\text { Link: https://sucupira.capes.gov.br/sucupira/public/consultas/coleta/ } \\
\text { trabalhoConclusao/viewTrabalhoConclusao.jsf?popup=true\&id_trabalho=4769503 }\end{array}$ \\
\hline 04.07 & $\begin{array}{l}\text { ANDRADE, M. O. Evasão escolar na educação de jovens e adultos: um estudo a partir da } \\
\text { escola Monsenhor Gilberto Vaz Sampaio I - Varzedo/BA. Cruz das Almas: Universidade } \\
\text { Federal do Recôncavo da Bahia, 2016. (Dissertação de Mestrado). } \\
\text { Link: https://sucupira.capes.gov.br/sucupira/public/consultas/coleta/ } \\
\text { trabalhoConclusao/viewTrabalhoConclusao.jsf?popup=true\&id_trabalho=4943762 }\end{array}$ \\
\hline 04.08 & $\begin{array}{l}\text { SANTOS, A. B. O abandono escolar em } 2 \text { escolas estaduais da CDE } 05 \text { de Manaus/AM. Juiz } \\
\text { de Fora: Universidade Federal de Juiz de Fora, 2017. (Dissertação de Mestrado). } \\
\text { Link: https://sucupira.capes.gov.br/sucupira/public/consultas/coleta/ } \\
\text { trabalhoConclusao/viewTrabalhoConclusao.jsf?popup=true\&id_trabalho=6062284 }\end{array}$ \\
\hline 04.09 & $\begin{array}{l}\text { MELO, T. C. V. Estudo sobre o desempenho escolar a partir dos aspectos evidenciados no } \\
\text { relação entre família e escola. Viçosa: Universidade Federal de Viçosa, 2018. (Dissertação } \\
\text { de Mestrado). } \\
\text { Link: https://sucupira.capes.gov.br/sucupira/public/consultas/coleta/ } \\
\text { trabalhoConclusao/viewTrabalhoConclusao.jsf?popup=true\&id_trabalho=6954736 }\end{array}$ \\
\hline 04.10 & $\begin{array}{l}\text { ALVES, E. J. Abandono no Ensino Médio: um estudo de caso sobre as ações gestoras } \\
\text { na escola Constâncio no município de Nacip Raydan - MG. Juiz de Fora: Universidade } \\
\text { Federal de Juiz de Fora, 2018. (Dissertação de Mestrado). } \\
\text { Link } \\
\text { https://sucupira.capes.gov.br/sucupira/public/consultas/coleta/trabalhoConclusao/ } \\
\text { viewTrabalhoConclusao.jsf?popup=true\&id_trabalho=6427964 }\end{array}$ \\
\hline
\end{tabular}

Fonte: Elaborado pelos autores. 
Entre os estudos analisados, quatro associaram o desinteresse escolar como um dos motivos de evasão escolar. Dois correlacionaram a falta de interesse com o abandono escolar. Em um trabalho o desinteresse escolar foi associado à indisciplina do estudante. Em outro foi trazida a reflexão de que a falta de interesse afetava o desempenho escolar. E, no último trabalho, o desinteresse escolar estava associado à exploração infantil. Isso posto, nesses estudos o desinteresse está atrelado a vários fatores, de forma semelhante ao que indicam outros trabalhos, a exemplo de Pozzobon, Mahendra, Marin (2017), Franco, Haddad e Silva (2011), Silva (2016) e Justi et al. (2019).

Das análises possíveis de serem feitas por meio dos resumos, destacamos, em primeiro lugar, os achados da dissertação 04.05, que indica alguns indícios de motivos que levam ao desinteresse ou desmotivação pelo ensino formal, tais como: a) influência da construção da autoestima, autoimagem e autoconceito; b) a construção do vínculo de pertencimento a um grupo; c) o formato do currículo padrão, que fortalece a educação bancária e não a emancipadora; d) necessidades de construir o cuidado de si, visando ao autoconhecimento por parte do professor.

Também salientamos a complexidade do tema desinteresse escolar. Conforme traz o resumo da dissertação 04.04, a falta de interesse pode estar ligada a diferentes variáveis associadas a muitos fatores como social, cultural, econômico, familiar, acadêmico. Isso nos auxilia a pensar no quão importante é estudar o tema, visto que ele pode ser resultado de uma série de questões sociais e culturais, não apenas a simples falta de vontade em aprender por parte do estudante. Nesse sentido Silva (2016), ao discutir especificamente a evasão escolar no Ensino Médio, argumenta que vários fatores interferem nessa questão. Como fator externo ao estudante o autor destaca a falta de políticas públicas comprometidas com a inclusão das classes mais pobres na escola, e como fator interno apresenta, com base em Silva (2013):

[...] a pobreza de famílias e estudantes, o nível cultural da família, a necessidade da busca por trabalho e a consequente dificuldade de conciliar trabalho e estudo, assim como o desconhecimento sobre o curso que faz, levando a não adequação e à insatisfação, a falta de formação dos professores para lidar com os alunos em situação de abandono, e, por fim, a falta de base educacional e de conteúdo do aluno, que gera repetência e desinteresse (SILVA, 2016, p. 32).

Consideramos ainda que tratar o fenômeno do desinteresse escolar com uma visão mais ampla e não somente centrada no aprendente nos faz refletir sobre estratégias eficazes para seu enfrentamento, que envolvem, entre outros aspectos, o desenvolvimento de políticas públicas educacionais com foco na inclusão e manutenção de todos os estudantes na escola.

Por fim, o trabalho 04.02 traz à tona outra temática importante, sobre a exploração sexual juvenil que pode influenciar no desinteresse escolar. Nos achados do estudo constatou-se que o abuso e a exploração juvenil podem causar implicações escolares, tais como: fragilização na formação escolar e no processo psicossocial de desenvolvimento juvenil; dificuldade de aprendizagem; desatenção nos conteúdos e atividades escolares; desinteresse pela escolarização (abandono e/ou repetência escolar). Nesse sentido, ressaltamos relevante a construção de estratégias de enfrentamento a esse tipo de exploração, em defesa dos direitos humanos das crianças e jovens. 


\section{CONSIDERAÇÕES FINAIS}

Este estudo buscou apresentar um panorama da produção acadêmica a respeito da temática "desinteresse escolar" a partir do mapeamento de teses e dissertações que abordam o assunto, disponíveis no catálogo da Capes, no período compreendido entre 2007 e 2018, a fim de sinalizar como este tema vem sendo estudado no âmbito da pesquisa. De modo geral, foi possível identificar que os focos de discussão dos estudos incluem: o desinteresse pela educação escolar, as implicações do desinteresse do estudante na prática docente, o desinteresse como uma construção histórico-social e o desinteresse associado a diversos fatores, como indisciplina e evasão.

A revisão da literatura possibilitou compreender, ainda, a necessidade e a importância de se estudar o desinteresse escolar, pois esta temática suscita várias reflexões sobre o contexto escolar, bem como sobre as trajetórias dos estudantes e o contexto sociocultural em que estamos inseridos. A partir dos resultados sistematizados nas categorias de análise, verificou-se que, apesar de a escola ser entendida como um espaço significativo para adquirir conhecimentos e ser uma "promessa para um futuro melhor", a falta de interesse dos estudantes é um fenômeno presente e que marca tanto a sua trajetória escolar quanto afeta a saúde mental do corpo docente. Foi possível inferir, ainda, que o desinteresse envolve, de acordo com os estudos, diferentes dimensões, podendo estar relacionado tanto a disciplinas específicas quanto ao processo de aprendizagem escolar de modo geral.

Não obstante, as discussões apresentadas nos trabalhos analisados indicam que embora a dimensão metodológica do fazer docente seja um fator que interfere e/ou desencadeia o desinteresse escolar, conforme evidenciado, principalmente, na categoria "desinteresse pela educação escolar", o enfrentamento do problema envolve vários aspectos, tão ou mais importantes que as metodologias de ensino. Parece urgente a necessidade de ressignificação dos tempos e espaços escolares, a proposição de currículos que levem em consideração a realidade dos estudantes, em uma perspectiva em que situações-problemas sejam compreendidas como objeto de estudo e investigação (FREIRE, 1987; DELIZOICOV; ANGOTTI; PERNAMBUCO, 2007). Ou seja, para além de discussões em torno do "como ensinar?", é relevante se considerar também "para quem?" e o "o quê?", uma vez que se entende, neste trabalho, que elementos advindos da investigação da realidade podem ser problematizados em sala de aula e potencializar o processo de ensino e aprendizagem.

Além disso, compreende-se que considerar o estudante como sujeito do conhecimento (DELIZOICOV; ANGOTTI; PERNAMBUCO, 2007) pode contribuir para o enfrentamento do desinteresse escolar. Nessa perspectiva, a aprendizagem é entendida como um processo protagonizado pelo sujeito/aluno, resultado da interação com o meio social e natural em que ele está inserido. Nesse contexto, o papel do professor é "mediar, criar condições, facilitar a ação do aluno de aprender, ao vincular um conhecimento como seu porta-voz" (DELIZOICOV; ANGOTTI; PERNAMBUCO, 2007, p. 122).

Considerar o aluno como sujeito do conhecimento também envolve: (i) analisar a relevância dos conteúdos a serem ensinados na escola, pois como evidenciado em alguns estudos analisados, os estudantes demonstram desmotivação por determinadas 
áreas do conhecimento, conforme discutido na subcategoria "desinteresse pela área do conhecimento" e (ii) pensar sobre quem é o estudante, em que contexto está inserido, quais suas expectativas, entre outros aspectos, porque como indicado nas categorias "desinteresse associado à indisciplina, abandono, evasão e desempenho escolar" e "desinteresse como uma construção histórico-social; ligado à aspectos sociais" a realidade do estudante interfere de forma direta na forma no desinteresse escolar.

Assim, apesar de a revisão realizada não ter contemplado o que se denomina de "estado da arte" (FERREIRA, 2002), e ter envolvido somente os resumos das teses e dissertações selecionadas, as conclusões obtidas a partir das quatro categorias analíticas enfocadas trazem importante parâmetros que permitem caracterizar, mesmo que ainda de forma limitada, como vem ocorrendo a discussão sobre a temática. Futuramente, o aprofundamento da análise, a partir da leitura na íntegra dos trabalhos, poderá trazer uma visão mais ampla.

Diante dessas considerações, salientamos a relevância de se investir em estratégias de enfrentamento do desinteresse escolar. Compreendemos, no entanto, que existe um longo caminho a ser percorrido para que sejam efetivadas estas práticas, uma vez que é necessário considerar o desinteresse não como algo reduzido, centrado apenas no estudante e/ou no professor, mas como um processo com implicações socioculturais, que demanda a construção de novas políticas públicas educacionais.

Em acréscimo, a temática escolhida nesta pesquisa não se esgota neste trabalho. Salientamos o investimento de estudos que possam vir agregar ao assunto, em especial os que possam ouvir pessoas atuantes no contexto escolar, tais como professores, gestores, família, comunidade, no sentido de aprofundar e enfrentar o desinteresse escolar e garantir o direito à educação de todo e qualquer estudante. Entendemos, portanto, que trazer à tona o tema desinteresse/desmotivação escolar pode auxiliar na construção de um cenário de mudanças e ajustes de diretrizes políticas, educacionais e sociais que permitam uma realidade pautada por condições favoráveis ao direito à educação e ao interesse dos estudantes nos processos educativos e na escola.

Além disso, com o avanço das reflexões sobre a democratização escolar e a difusão das políticas sociais que incentivam o direito à educação, identificar como o tema desinteresse tem sido contextualizado em trabalhos acadêmicos tem potência em pautar reflexões sobre a atuação, articulação e o envolvimento de diferentes agentes que agem em prol do enfrentamento ao desinteresse escolar.

\section{REFERÊNCIAS}

ANGELUCCI, C. B.; KALMUS, J.; PAPARELLI, R.; PATTO, M. H. S. O Estado da Arte da pesquisa sobre o fracasso escolar (1991-2002): um estudo introdutório. Educação e Pesquisa, v. 30, n. 1, p. 51-72, 2004. Disponível em: http://www.scielo.br/scielo.php?script=sci_arttext\&pid=S1517-97022004000100004.

BARREIROS, J. L. Fatores que influenciam na motivação de professores. Brasília: Centro Universitário de Brasília, 2008. Trabalho (Conclusão de Curso). Disponível em: https://repositorio.uniceub.br/jspui/bitstream/123456789/2581/2/20312042.pdf.

BAZILIO, R. M. G. O desinteresse dos alunos e o papel dos pais com o processo ensino-aprendizagem no contexto da gestão escolar. 2009. Monografia (Especialização) - Universidade Federal de Santa Maria, Cruzeiro do Oeste, 2009. Disponível em: https://repositorio.ufsm.br/handle/1/1272. 
BITENCOURT, L. P.; BATISTA, M. L. S. Educação matemática e o "desinteresse" do aluno: causa ou consequência? In: CONGRESSO NACIONAL DE EDUCAÇÃO MATEMÁTICA, 2., 2011. Atas [...]. 2011. Disponível em: http://www.projetos.unijui.edu.br/matematica/cnem/cnem/principal/cc/PDF/CC44.pdf.

BRASIL. Projeto de Lei no 8.035 de 2010. Aprova o Plano Nacional de Educação para o decênio 2011-2020 e dá outras providências. Brasília: Câmara dos Deputados, 2010. Disponível em: http://portal.mec.gov.br/ index.php?option $=$ com_content\&id=16478\& Itemid $=1107$.

BRASIL. Lei de 27 de outubro de 2009. Altera o inciso II do art. 4o e o inciso VI do art. 10 da Lei no 9.394, de 20 de dezembro de 1996, para assegurar o acesso de todos os interessados ao ensino médio público. Disponível em: http://www.planalto.gov.br/ccivil_03/_Ato2007-2010/2009/Lei/L12061.htm.

BRASIL. Lei no 5.692 de 11 de agosto de 1971. Fixa Diretrizes e Bases para o ensino de $1^{\circ}$ e $2^{\circ}$ graus, e dá outras providências. Disponível em: https://www2.camara.leg.br/legin/fed/lei/1970-1979/lei-5692-11-agosto-1971-357752-publicacaooriginal-1-pl.html.

BRASIL. Lei no 9.394, de 20 de dezembro de 1996. Lei de Diretrizes e Bases da Educação Nacional. Brasília, 1996. Disponível em: http://portal.mec.gov.br/seesp/arquivos/pdf/lei9394_ldbn1.pdf.

CIMA, R. C.; ROCHA FILHO, J. B.; FERRARO, J. L. S.; LAHM, R. A. Redução do interesse pela física na transição do Ensino Fundamental para o Ensino Médio: a perspectiva da supervisão escolar sobre o desempenho dos professores. Revista Electrónica de Enseñanza de las Ciencias, v. 16, p. 385-409, 2017. Disponível em: http://meriva.pucrs.br/dspace/handle/10923/11802.

CURY, C. R. J. Direito à educação: direito à igualdade, direito à diferença. Cadernos de Pesquisa, n. 116, p. 245-262, 2002.

DELIZOICOV, D.; ANGOTTI, J. A.; PERNAMBUCO, M. C. A. Ensino de ciências: fundamentos e métodos. São Paulo: Cortez, 2007.

FERREIRA, N. S. A. As pesquisas denominadas estado da arte. Educ. Soc., ago. 2002, v. 23, n. 79, p. $257-$ 272. Disponível em: http://www.scielo.br/pdf/es/v23n79/10857.pdf.

FRANCO, A. F.; HADDAD, C. R.; SILVA, D. Evasão escolar: uma análise do Programa Fica. In: LEONARDO, Nilza Sanches Tessaro; LEAL, Zaira Fátima de Rezende Gonzales (org.). Educação escolar e apropriação do conhecimento: questões contemporâneas. Maringá: Eduem, 2011. p. 49-66. Disponível em: https://educere.bruc.com.br/CD2011/pdf/4204_2327.pdf.

FREIRE. Pedagogia do oprimido. Rio de Janeiro: Paz e Terra, 1987.

IBGE. Instituto Brasileiro de Geografia e Estatística. Pesquisa Nacional por Amostra de Domicílios (PNAD) 2018. Disponível em: https://agenciadenoticias.ibge.gov.br/agencia-sala-de-imprensa/2013-agencia-de-noticias/releases/25700-pnad-continua-2018-10-da-populacao-concentram-43-1-da-massa-de-rendimentos-do-pais.

INEP. Instituto Nacional de Estudos e Pesquisas Educacionais Anísio Teixeira. Censo Escolar 2017. Disponível em: http://download.inep.gov.br/educacao_basica/censo_escolar/notas_estatisticas/2018/notas_estatisticas_Censo_Escolar_2017.pdf.

JUSTI, J.; FREITAS, F. M. P. R.; OLIVEIRA, H. X.; VASCONCELOS, C. F. C. Fatores que influenciam o desempenho escolar de adolescentes de uma instituição pública do município de Rio Verde, GO. In: EDITORA POISSON (org.). Educação no século XXI - gestão e políticas públicas. Belo Horizonte: Editora Poisson, 2019. p. 78-83. V. 8. Disponível em: https://educere.bruc.com.br/arquivo/pdf2017/23049_11679.pdf.

KRAPP A.; LEMOS. Os interesses dos alunos como condição e como objetivo da aprendizagem escolar. In: LEMOS, M. S.; CARVALHO, T. R. (org.). O aluno em sala de aula. Porto: Porto Editora, 2002. p. 77-104.

LÜDKE, M.; ANDRÉ, M.E.D.A. Pesquisa em educação: abordagens qualitativas. São Paulo: Ed. Pedagógica e Universitária - EPU, 1986.

MARIANO, G. S.; MIRANDA, J. L. A.; METZNER, A. C. Fatores que levam ao desinteresse dos alunos do Ensino Médio em participar das aulas de Educação Física. Revista Educação Física - Unifafibe, v. V, p. 7-18, 2017. Disponível em: http://repositorio.unesc.net/handle/1/1523.

MARSHALL, T. Cidadania, classe social e status. Rio de Janeiro: Zahar, 1967.

MORALES, M. L.; ALVES, F. L. O desinteresse dos alunos pela aprendizagem: uma intervenção pedagógica. In: Os desafios da escola pública paranaense na perspectiva do professor (Revista), Paraná: Secretaria da Educação, 2016. Disponível em: http://www.diaadiaeducacao.pr.gov.br/portals/cadernospde/pdebusca/ producoes_pde/2016/2016_artigo_ped_unioeste_marciadelourdesmorales.pdf.

OLIVEIRA, T. K. B. Desmotivação: um fator negativo na prática do professor. Revista Senso Comum, n. 1, p. 76-85, 2009. 
POZZOBON, M.; MAHENDRA, F.; MARIN, A. H. A. Renomeando o fracasso escolar. Psicologia escolar e educacional, n. 3, v. 21, p. 387-396, 2017. Disponível em: http://www.scielo.br/pdf/pee/v21n3/21753539-pee-21-03-387.pdf.

REGO, T. C. Memórias de escola: cultura escolar e constituição de singularidades. Petrópolis: Vozes, 2003. SANTOS, Elenir Souza. Trabalhando com alunos: subsídios e sugestões: o professor como mediador no processo ensino aprendizagem. Revista do Projeto Pedagógico; Revista Gestão Universitária, n. 40. Disponível em: http://www.udemo.org.br/RevistaPP_02_05Professor.htm. Acesso em: 9 jan. 2020.

SILVA, P. J. Interest The Curious Emotion. Current Directions in Psychological Science, Washington, DC, 1, v. 17, n. 1, p. 57-60, fev. 2008.

SILVA, D. N. A desmotivação do professor em sala de aula, nas escolas públicas do município de São José dos Campos - SP. 2012. Monografia (Especialização) - Universidade Tecnológica Federal do Paraná, Curitiba, 2012. Disponível em: http://repositorio.roca.utfpr.edu.br/jspui/bitstream/1/1822/1/CT_GPM_ II_2012_87.pdf.

SILVA, W. A. Fatores de permanência e evasão no Programa de Educação Profissional de Minas Gerais (PEP/MG). 2013. Tese (Doutorado) - Universidade Federal de Minas Gerais, Belo Horizonte, 2013.

SILVA, W. A. Evasão escolar no Ensino Médio no Brasil. Educação em Foco, n. 29. v. 9, p. 13-34, 2016.

SILVA, V.; FERNANDES, F. S.; SILVA, R. S. Afinal, o que é, no contemporâneo, uma sala de aula? Hipertextus Revista Digital, v. 16, jun. 2017. Disponível em: http://www.hipertextus.net/volume16/Art1Vol16.pdf. 